Pol. J. Food Nutr. Sci., 2021, Vol. 71, No. 3, pp. 299-310

On-line ISSN: 2083-6007

Print ISSN: 1230-0322

DOI: $10.31883 /$ pjfns/140404 http://journal.pan.olsztyn.pl

Original article

Section: Food Technology

\title{
Optimized Extraction, Microencapsulation, and Stability of Anthocyanins from Ardisia compressa K. Fruit
}

\author{
María Vianey Antonio-Gómez ${ }^{1}$, Yolanda Salinas-Moreno ${ }^{2 *}{ }^{\odot}$, Francisco Hernández-Rosas ${ }^{1}{ }^{\oplus}$, \\ Fernando Martínez-Bustos ${ }^{3}{ }^{\circledR}$, Isaac Andrade-González ${ }^{4}{ }^{\circledR}$, José Andrés Herrera-Corredor ${ }^{1}{ }^{\circledR}$
}

${ }^{1}$ Postgraduate College, Campus Cordoba. Postgraduate in Sustainable Agrifood Innovation, Km 348 carretera Córdoba-Veracruz, 94946, Amatlán de los Reyes, Veracruz, Mexico

${ }^{2}$ National Institute of Forestry, Agriculture and Livestock Research, Experimetal Field Centro Altos de Jalisco, Km 8 carretera Tepatitlán-Lagos de Moreno, Tepatitlán de Morelos, CP 47600 Jalisco, Mexico

${ }^{3}$ Center for Research and Advanced Studies of the National Polytechnic Institute, Campus Querétaro, Libramiento

Norponiente No. 2000, Fraccionamiento Real de Juriquilla, CP 76230 Santiago de Querétaro, Querétaro, Mexico

${ }^{4}$ Technological Institute of Tlajomulco, Jalisco, Agri-Food processes pilot plant,

Km 10 carr. A San Miguel, Cuyutlán, Tlajomulco de Zúñiga, CP 45640 Jalisco, Mexico

Key words: Ardisia compressa K., tropical fruit, microcapsules, anthocyanins, spray drying

The fruit of Ardisia compresssa K. is called chagalapoli and has a high anthocyanin content, with a profile dominated by malvidin derivatives. The aims of this study were: a) to determine optimal conditions (ethanol concentration, $\mathrm{pH}$, and sonication time) for anthocyanin extraction from chagalapoli fruit (CF) using response surface methodology, b) to perform spray-drying microencapsulation of the anthocyanins using mixtures of polysaccharides (maltodextrin - $\mathrm{M}$ and $\mathrm{Capsul}^{\circledR}-\mathrm{C}$ ) as wall materials, and c) to evaluate the stability of microcapsules during storage. Of the variables examined to optimize anthocyanin extraction from $\mathrm{CF}$, only ethanol concentration and $\mathrm{pH}$ were significant in the model. The optimal extraction conditions were: $63.5 \%(\mathrm{v} / \mathrm{v})$ ethanol, $\mathrm{pH}$ of 2.0, and sonication time of $30 \mathrm{~min}$, which led to an anthocyanin content of 1545 mg malvidin 3-O-galactoside equivalents/100 $\mathrm{g}$ of fresh fruit. The proportion of $\mathrm{M} / \mathrm{C}$ as the wall materials for microcapsule $(\mathrm{MC})$ preparation did not affect the encapsulation efficiency and anthocyanin retention, but high hygroscopicity was observed in the $\mathrm{MC}$ with a high proportion of $\mathrm{M}$. The half-life of the $\mathrm{MC}$ ranged from 423 to 519 days, and no effect of wall materials was observed. The color stability of the $\mathrm{MC}$ was enhanced by increasing $\mathrm{C}$ proportion in wall materials. The high stability of microencapsulated anthocyanins of chagalapoli fruit makes it a suitable option as a food colorant.

\section{INTRODUCTION}

Nowadays, the food industry has an increasing demand for natural pigments prompted by the banning of most synthetic colorants commonly used in food products [Luzardo-Ocampo et al., 2021], and by consumer preferences for products without artificial colorants. Anthocyanins are vegetal pigments related with shades of pink, red, blue, and purple colors, that are easily incorporated in food matrices due to their water solubility [Giusti \& Wrolstad, 2003]. They also represent an alternative to synthetic dyes. Besides being pigments, anthocyanins possess several biological activities such as antioxidative, antimutagenic, and anti-inflammatory ones [Bendokas et al., 2020].

In the process of incorporating a new vegetal source of pigments, it is necessary to determine the most suitable combinations of factors relating to anthocyanin recovery, as these

\footnotetext{
* Corresponding Author:

Tel.: +52 01800088 2222, ext:84501

E-mail: salinas.yolanda@inifap.gob.mx (Y. Salinas-Moreno)
}

factors affect the performance and profitability of the extraction, and also the type of phenolics extracted [Najafabadi et al., 2020] and their stability [Pedro et al., 2016]. Among the factors most studied in anthocyanin extraction are: solid to solvent ratio [Pedro et al., 2016], solvent type, and temperature [Ghafoor et al., 2011], extraction time [Najafabadi et al., 2020], and pH [Rodrigues et al., 2015]. The effect of the extraction conditions on the anthocyanin yield and composition of the extract depends on the matrix [Najafabadi et al., 2020]; therefore, it is recommended to adjust the conditions for each particular material.

The instability of anthocyanins to several factors commonly present during food processing, such as changes in $\mathrm{pH}$, heating, exposure to light and oxygen, presence of metal ions, and enzymes [Tarone et al., 2020], has limited their use as food colorants. The instability has been overcome with encapsulation technology, which permits to obtain microspheres.

Submitted: 14 January 2021 Accepted: 20 July 2021 Published on-line: 20 August 2021 
The microspheres or microcapsules have a wall that protects the active compound from external factors. In the case of anthocyanins, different encapsulation wall materials, i.e. gums, polysaccharides, and lipids or proteins, have been tested [Tarone et al., 2020], on their own or in combination of two or more wall materials, to achieve the required properties that ensure satisfactory microencapsulation [Turchiuli et al., 2005]. The selection of suitable wall materials is an important step in the microencapsulation process because of its effect on the microcapsule surface and stability.

Spray-drying is one of the most popular and economical techniques used in the industry to microencapsulate food ingredients [Tarone et al., 2020]. For its application, it is necessary that the wall materials have emulsifying properties, with high solubility and low hygroscopicity [Loksuwan, 2007]. Carbohydrates of low molecular weight compounds have these properties. Maltodextrin is one of the most commonly used materials due to its high solubility and low viscosity [Tonon et al., 2010]. Furthermore, Capsul ${ }^{\circledR}$, a starch that has been chemically modified through the incorporation of a lipophilic component (octenylsuccinate), has excellent stability and emulsifying properties [Rocha et al., 2012].

The stability of microcapsules is determined by such features as shape, integrity, porosity, and moisture sorption characteristics. The right combinations of these features make it possible that microcapsules retain the compounds they protect for a reasonable time, when they are stored under room conditions.

Several tropical fruits have been identified as potential sources of anthocyanins [de Brito et al., 2007]. One of these is the fruit of Ardisia compressa $\mathrm{K}$. (ACK), known as chagalapoli, which has a high anthocyanin content (natural pigment) [Joaquín-Cruz et al., 2015]. Recently, anthocyanins from chagalapoli fruit (CF) were used to prepare nanoparticles with succinated starch as a wall material [Escobar-Puentes et al., 2020]. However, limited information is available about the optimal conditions for extracting the anthocyanins from $\mathrm{CF}$, nor on the most suitable combination of wall materials for microencapsulating the anthocyanins from this fruit. In this context, the aims of this study were: a) to optimize the extraction of anthocyanins from CF, b) to microencapsulate the anthocyanins using maltodextrin and $\mathrm{Capsul}^{\circledR}$ mixtures as wall materials, and c) to evaluate the stability of the microcapsules.

\section{MATERIALS AND METHODS}

\section{Reagents and plant material}

The chemicals included analytical grade ethanol, hydrochloric acid, formic acid, and methanol (J.T. Baker, Phillipsburg, NJ, USA). HPLC-grade water and methanol (J.T. Baker, Phillipsburg, NJ, USA) were used for the analysis of anthocyanins as part of the mobile phases used. Commercial standards of delphinidin 3-O-galactoside (Dp 3-Gal) and malvidin 3-O-galactoside (Mv 3-Gal) were used (Extrasynthese, Genay, France) for running standard curves. The wall materials were 10 DE maltodextrin (IMSA, SA de CV, Guadalajara, Mexico), and Capsul ${ }^{\circledR}$ (Ingredion, Guadalajara, Mexico).

The plant material consisted of $3 \mathrm{~kg}$ of ripe fruits of chagalapoli (A. compressa) obtained from the regional market
TABLE 1. Ranges and levels of independent process variables considered in the Box-Behnken design.

\begin{tabular}{l|c|c|c|c}
\hline \multirow{2}{*}{ Independent variable } & \multirow{2}{*}{ Factors } & \multicolumn{3}{|c}{ Coded levels } \\
\cline { 3 - 5 } & & -1 & 0 & 1 \\
\hline Solvent pH & $\mathrm{A}$ & 2 & 2.5 & 3 \\
Ethanol concentration (\%) & $\mathrm{B}$ & 50 & 75 & 100 \\
Sonication time (min) & $\mathrm{C}$ & 10 & 20 & 30 \\
\hline
\end{tabular}

of San Andres Tuxtla, Veracruz, Mexico. The seed was removed, and the fruit pulp was homogenized using an Ultra Turrax homogenizer (T-10 Basic, IKA, Wilmington, NC, USA) for one min at a speed of 20,450 rpm.

\section{Optimization of anthocyanin extraction}

Response surface methodology (RSM) was used to optimize the extraction conditions of anthocyanins from CF. According to the preliminary tests, the optimal proportion of fruit pulp/solvent was established as 1:5 $(w / v)$. The experimental design was based on a Box-Behnken design with three factors $-\mathrm{pH}(\mathrm{A})$, ethanol concentration (B), and sonication time (C) - with three replicates each. The response variable was the total anthocyanin content (TAC). The experimental design resulted in 15 treatments (T1 to T15) with the details of the factors and levels provided in Table 1.

Two grams of the homogenized fruit pulp and $10 \mathrm{~mL}$ of a solvent (aqueous ethanol) were used for each treatment. After sonication, the sample of each treatment was stirred for $30 \mathrm{~min}$ in a horizontal shaker at room temperature under dark conditions. Extracts were recovered by centrifugation (Centrifuge Universal Model 32. Hettich ${ }^{\circledR}$, Tuttlingen, Germany) of the sample at $2558 \times \mathrm{g}$ for $10 \mathrm{~min}$, and the total anthocyanin content (TAC) was determined with the methodology described by Moreno et al. [2005]. Briefly, the absorbance of the extract was measured at $530 \mathrm{~nm}$ using a spectrophotometer (Lambda 25 UV/Vis, Perkin Elmer. Waltham, MA, USA). A standard curve of malvidin 3-O-galactoside was obtained to express the results as $\mathrm{mg} \mathrm{Mv} \mathrm{3-Gal} \mathrm{equivalents/100} \mathrm{g}$ fresh weight (FW).

A second-order polynomial model was constructed to estimate the response of TAC to the different extraction treatments (Equation 1). In the equation, " $y$ " is the estimated response (dependent variable); $\beta_{0}$ is a constant in the model; $\beta_{\mathrm{i}}$ is the linear effect coefficient; $\beta_{\mathrm{ii}}$ is the quadratic effect coefficient; $\beta_{\mathrm{ij}}$ is the coefficient of the interaction between two factors; $x_{\mathrm{i}}$ and $x_{\mathrm{j}}$ are the independent variables; $k$ is the number of variables considered, and $i$ and $j$ are the factors coded into the system [Swamy et al., 2014].

$$
\begin{aligned}
y=\beta_{0} & +\sum_{i=1}^{k} \beta_{i} \times x_{i}+\sum_{i=1}^{k} \beta_{i i} \times \\
& \times x_{i}^{2}+\sum_{i=1}^{k-1} \sum_{j>1}^{k} \beta_{i j} \times x_{i} \times x_{j}
\end{aligned}
$$

\section{HPLC analysis of the anthocyanin extract}

A Perkin-Elmer ${ }^{\circledR}$ Series 200 instrument, operated with TotalChrome software and consisting of a photodiode array detector, a quaternary pump, and an autosampler with one thermostatted 
column compartment was used (PerkinElmer ${ }^{\circledR}$ Instruments LLC, Shelton, CT, USA). A C18 ODS Hypersil $(200 \times 4.6 \mathrm{~mm})$ column with a particle size of $5 \mu \mathrm{m}$ (Thermo Fisher Scientific ${ }^{\circledR}$, Carlsbad, CA, USA) was employed for the separation of chagalapoli anthocyanins obtained under the optimized extraction conditions. The extract was filtered through a $0.20 \mu \mathrm{m}$ Millex-LG ${ }^{\circledR}$ membrane filter (Millex PTFE, 4 mm, Sigma-Aldrich, Toluca, Mexico) prior to injection. The analysis was performed according to the method of Fossen et al. [2001], with the adjustments described by Moreno et al. [2005] in a system of gradients. Two solvents were used: A $(1: 9, v / v)$ (formic acid/water) and B (1:4:5, $v / v / v$ ) (formic acid/water/methanol). The gradient was linear from $10 \%$ B to $100 \%$ B for $17 \mathrm{~min}$, isocratic elution for the next 4 min (100\% B), followed by a linear gradient from $100 \%$ B to $10 \%$ B for $1 \mathrm{~min}$, with an equilibrium time of $4 \mathrm{~min}$, before the next injection. The flow rate was $1.2 \mathrm{~mL} / \mathrm{min}$ with an injection volume of $10 \mu \mathrm{L}$ and a column temperature of $30^{\circ} \mathrm{C}$. Anthocyanins were identified by the use of commercial standards, and by comparison with the information reported by Joaquín--Cruz et al. [2015].

\section{Spray-drying microencapsulation of anthocyanins}

The anthocyanin extract obtained under the optimized extraction conditions was used for analyses. It was concentrated in a rotary evaporator system to remove ethanol. The carbohydrates used as wall materials were maltodextrin $10 \mathrm{DE}(\mathrm{M})$ and Capsul ${ }^{\circledR}(\mathrm{C})$. Five treatments of different proportions of each carbohydrate in a weight ratio were prepared including $100 \% \mathrm{M}(100 \mathrm{M})$ and $100 \% \mathrm{C}(100 \mathrm{C})$ and combinations of $\mathrm{M}$ and $\mathrm{C}: 75 \% \mathrm{M}$ and $25 \% \mathrm{C}(75 \mathrm{M} 25 \mathrm{C}), 50 \% \mathrm{M}$ and $50 \% \mathrm{C}$ (50M50C), and 25\% $\mathrm{M}$ and $75 \% \mathrm{C}$ (25M75C).

A suspension of extract and wall materials was prepared at a final concentration of $20 \%(w / v)$. Fifty grams of wall material were dissolved in $200 \mathrm{~mL}$ of distilled water and homogenized in a blender (Waring ${ }^{\circledR}$ brand) for 1 min at a low speed. Thereafter, $50 \mathrm{~mL}$ of concentrated extract was added and homogenized with an Ultra Turrax homogenizer (Wilmington, NC. USA) at 18,000 rpm for $5 \mathrm{~min}$. Encapsulation was performed in a spray dryer (SD-Basic Lab-Plant, Huddersfield, UK) under the following conditions: inlet air temperature of $160 \pm 1^{\circ} \mathrm{C}$, outlet air temperature of $95 \pm 5^{\circ} \mathrm{C}$, pressure of $241.3 \mathrm{KPa}$, nozzle diameter of $0.5 \mathrm{~mm}$, and a feed stream of $10 \mathrm{~mL} / \mathrm{min}$. These conditions were selected based on preliminary experiments by the authors. The microcapsules (MC) were collected in plastic bags, weighed, and stored in a desiccator, under darkness, at room temperature.

\section{Efficiency of microencapsulation process and characterization of the microcapsules}

The encapsulation efficiency (EE) was determined according to the methodology used by García-Tejeda et al. [2015]. The experimental content of total anthocyanins $\left(\mathrm{TAC}_{\mathrm{e}}\right.$ ) was determined with the method of differential $\mathrm{pH}$ [Giusti \& Wrolstad, 2001], and the results were expressed as mg Mv 3-Gal equivalents/g of microcapsules using a molar extinction coefficient of $28,000 \mathrm{~L} /(\mathrm{mol} \cdot \mathrm{cm})$ and a molecular weight of $463.3 \mathrm{~g} / \mathrm{mol}$.

Extraction of superficial anthocyanins was determined according to the modified method of Robert et al. [2010], in which $500 \mathrm{mg}$ of microcapsules were treated with $10 \mathrm{~mL}$ of isopropanol and dispersed by vortexing at room temperature for one min and then filtered (Millipore $0.45 \mu$ filter). The EE was calculated using Equation (2):

$$
E E=1-\frac{S A C}{T A C_{e}} \times 100
$$

where: $T A C_{\mathrm{e}}$ is the experimental content of total anthocyanins and $S A C$ is the content of superficial anthocyanins; all values are expressed as $\mathrm{mg} / \mathrm{g}$ of $\mathrm{MC}$.

\section{Moisture content and water activity}

The moisture content (MT) of the MC was determined according to AACC Method 44-19 [AACC, 1995]. The water activity $\left(\mathrm{a}_{\mathrm{w}}\right.$ ) was measured with an Aqualab ${ }^{\circledR}$ device (Model Series 3TE, Decagon Devices, Pullman, WA, USA).

\section{Hygroscopicity and solubility}

The hygroscopicity $(\mathrm{H})$ of the MC was determined according to Tonnon et al. [2009]. Briefly, $1 \mathrm{~g}$ of MC was placed in a jar with an $\mathrm{NaCl}$ saturated solution (76\% relative humidity) at $25^{\circ} \mathrm{C}$. After one week, the samples were weighed, and the hygroscopicity was expressed as $\mathrm{g}$ of absorbed moisture per $100 \mathrm{~g}$ of dry solids. The solubility of MC was evaluated with the method described by Arrazola et al. [2014], in which $1 \mathrm{~g}$ of $\mathrm{MC}$ was poured in $100 \mathrm{~mL}$ of distilled water and stirred to dissolve. The sample was centrifuged for $10 \mathrm{~min}$ at $1409 \times \mathrm{g}$, and $25 \mathrm{~mL}$ of the supernatant was placed in a glass capsule to evaporate the liquid in an oven at $105^{\circ} \mathrm{C}$ for $5 \mathrm{~h}$. Solubility (\%) was calculated by weight difference.

\section{Scanning electron microscopy and particle size determination}

The external morphology of MC was evaluated by laser microscopy (OLS4000 LEXT ${ }^{\circledR}$ 3D, Olympus, Tokyo, Japan) and scanning electron microscopy (ESEM EDAX ${ }^{\circledR}$, GSE detector, Philips, Netherlands) coupled with energy dispersive spectrometry (spectrometer model 6110 XFlash $^{\circledR}$, Bruker corporation, Billerica, MA, USA) using an acceleration voltage of $15 \mathrm{kV}$. The samples were fixed to double-sided metal adhesive tape, and coated with a 10 to $15 \mathrm{~nm}$ graphite film via evaporation for one min. The Image Pro PLUS ${ }^{\circledR}$ version 7.0 (Media Cybernetics, Inc., Rockville, MD, USA) software was used to determine the diameter of the microcapsules via image processing.

\section{Anthocyanin stability during storage}

The stability of the anthocyanins in the MC was evaluated using the accelerated shelf life method proposed by Labuza \& Schmidl [1985]. In brief, approximately $500 \mathrm{mg}$ of MC of each treatment were put in Eppendorf tubes which were sealed with aluminum foil to protect them from light, and placed in a rack. The rack with the tubes was placed in an oven at $35^{\circ} \mathrm{C}$. The TAC of the $\mathrm{MC}$ was monitored every seven days during a 70-day period, using the differential $\mathrm{pH}$ method [Giusti \& Wrolstad, 2001]. The analysis was done in triplicate. The color of the MC was determined with a HunterLab MiniScan EZ 4500L spectrophotometer (Hunter Associates. Reston, VA, USA) in the CIE $\mathrm{L}^{*} \mathrm{a}^{*} \mathrm{~b}^{*}$ scale at day 0 , and after 70 days of storage. The following 
TABLE 2. Box-Behnken experimental design (different extraction conditions) and response values for the total anthocyanin content (TAC) of chagalapoli fruit.

\begin{tabular}{|c|c|c|c|c|c|}
\hline Treatment & $\mathrm{pH}$ & $\begin{array}{c}\text { Ethanol } \\
\text { concentration (\%) }\end{array}$ & $\begin{array}{l}\text { Sonication time } \\
(\text { min })\end{array}$ & $\begin{array}{c}\text { Experimental TAC } \\
\text { (mg Mv3-Gal/100 g FW*) }\end{array}$ & $\begin{array}{c}\text { Predicted TAC } \\
\text { (mg Mv3Gal/100 g FW) }\end{array}$ \\
\hline $\mathrm{T} 1$ & 2.0 & 75 & 30 & $1557 \pm 31$ & 1466 \\
\hline $\mathrm{T} 2$ & 2.5 & 100 & 30 & $206 \pm 6$ & 244 \\
\hline $\mathrm{T} 3$ & 3.0 & 50 & 20 & $652 \pm 25$ & 598 \\
\hline $\mathrm{T} 4$ & 2.0 & 100 & 20 & $325 \pm 36$ & 378 \\
\hline T5 & 3.0 & 75 & 30 & $822 \pm 36$ & 887 \\
\hline T6 & 2.5 & 75 & 20 & $1166 \pm 43$ & 1103 \\
\hline $\mathrm{T} 7$ & 2.0 & 75 & 10 & $1422 \pm 47$ & 1357 \\
\hline $\mathrm{T} 8$ & 3.0 & 75 & 10 & $825 \pm 11$ & 917 \\
\hline T9 & 3.0 & 100 & 20 & $190 \pm 8$ & 89 \\
\hline $\mathrm{T} 10$ & 2.5 & 75 & 20 & $1044 \pm 43$ & 1103 \\
\hline $\mathrm{T} 11$ & 2.5 & 100 & 10 & $218 \pm 10$ & 228 \\
\hline T12 & 2.5 & 75 & 20 & $1100 \pm 21$ & 1103 \\
\hline $\mathrm{T} 13$ & 2.0 & 50 & 20 & $1227 \pm 4$ & 1328 \\
\hline T14 & 2.5 & 50 & 30 & $1008 \pm 14$ & 998 \\
\hline T15 & 2.5 & 50 & 10 & $972 \pm 7$ & 934 \\
\hline
\end{tabular}

*FW - fresh weight.

parameters: luminosity ( $\mathrm{L}^{*}$, with 0 for black and 100 for white); $\mathrm{a}^{*}\left(+\mathrm{a}^{*}\right.$, red color; $-\mathrm{a}^{*}$, green color $)$; and $\mathrm{b}^{*}\left(+\mathrm{b}^{*}\right.$, yellow color; $-b^{*}$, blue color) were obtained with the equipment. The measurements were done in triplicate.

The degradation of the anthocyanins in the MC was studied with the first-order kinetic model. The value of the degradation constant $(k)$ was determined according to Equation (3):

$$
\ln \left(C_{t}\right)=\ln C_{0}-k(t)
$$

where: $C_{\mathrm{t}}$ is TAC of MC at time t; $C_{0}$ is initial TAC of the MC; and $t$ is storage time. The half-life of the MC was determined according to Equation (4), at the specific storage temperature.

$$
t_{1 / 2}=-\ln (0.5) / k T
$$

where: $t_{1 / 2}$ is the half-life time of anthocyanins in the MC; $k$ is the kinetic degradation constant; and $T$ is storage temperature [Idham et al., 2012].

Anthocyanin retention (AR) was determined using the equation:

$$
A R(\%)=100-A L(\%)
$$

where: $A L$ is the loss of anthocyanins at the time $t$ and was calculated using the following equation:

$$
A L(\%)=\left[1-\frac{C_{t}}{C_{0}}\right] \times 100
$$

\section{Statistical analysis}

The statistical analysis of data from optimized anthocyanin extraction were performed using Statgraphics Centurion version 16.1 (Manugistics Inc., Statistical Graphics Corporation, Rockville, MD, USA) software. Data from efficiency of microencapsulation and MC characteristics and color changes during storage were analyzed by one-way analysis of variance (ANOVA) and comparison Tukey's tests $(p<0.05)$ were performed using the statistical package SAS version 9.1 .

\section{RESULTS AND DISCUSSION}

\section{Optimization of anthocyanins extraction}

The TAC for all 15 treatments, and those calculated using the response surface model are shown in Table 2. The TAC ranged from 190 to $1557 \mathrm{mg} \mathrm{Mv} \mathrm{3-Gal} \mathrm{equivalents/100} \mathrm{g} \mathrm{FW}$ for $\mathrm{T} 9$ and $\mathrm{T} 1$ treatments, respectively. The differences in TAC between these two treatments show the importance of selecting the suitable levels of the factors involved in anthocyanin extraction. The experiments that resulted in the highest anthocyanin recovery included $\mathrm{T} 1, \mathrm{~T} 7$, and $\mathrm{T} 13$, which utilized a pH value of 2 and ethanol percentage between 50 and $75 \%$.

The ANOVA showed a coefficient of determination $\left(\mathrm{R}^{2}\right)$ of 0.9760 , indicating that the quadratic model was consistent with the experimental data. In addition, the adjusted value of $\mathrm{R}^{2}(0.9634)$ showed a high correlation between the experimental values and the predicted values for the recovery of anthocyanins (Table 3). 
TABLE 3. Analysis of variance of the effect of the process variables, as linear and quadratic terms, and the interactions, on the optimization of anthocyanin extraction from chagalapoli fruit.

\begin{tabular}{|c|c|c|c|c|c|}
\hline Source & Sum of squares & $\mathrm{df}$ & Mean square & F statistic & P-value \\
\hline A: $\mathrm{pH}$ & $1.04 \mathrm{E}+06$ & 1 & $1.04 \mathrm{E}+06$ & 148.58 & $<0.0001$ \\
\hline B: Ethanol concentration (\%) & $2.13 \mathrm{E}+06$ & 1 & $2.13 \mathrm{E}+06$ & 304.41 & $<0.0001$ \\
\hline C: Sonication time (min) & 6184.64 & 1 & 6184.64 & 0.88 & 0.359 \\
\hline $\mathrm{AB}$ & 97121.5 & 1 & 97121.5 & 13.88 & 0.0014 \\
\hline $\mathrm{AC}$ & 9546.17 & 1 & 9546.17 & 1.36 & 0.2573 \\
\hline $\mathrm{BC}$ & 1153.44 & 1 & 1153.44 & 0.16 & 0.6893 \\
\hline $\mathrm{AA}$ & 4710.25 & 1 & 4710.25 & 0.67 & 0.4222 \\
\hline $\mathrm{BB}$ & $2.07677 \mathrm{E}+06$ & 1 & $2.0768 \mathrm{E}+06$ & 296.7 & $<0.0001$ \\
\hline $\mathrm{CC}$ & 5734.1 & 1 & 5734.1 & 0.82 & 0.3767 \\
\hline Total error & 132992 & 19 & 6999.56 & & \\
\hline Total & $5.56 \mathrm{E}+06$ & 29 & & & \\
\hline
\end{tabular}

\begin{tabular}{ll}
\hline $\mathrm{R}^{2}=0.9760$ & Adjusted $\mathrm{R}^{2}=0.9634$ \\
\hline
\end{tabular}

df - degrees of freedom.

The adjusted model that predicts the response of TAC is shown in Equation 7, where $y$ is TAC.

$$
\begin{aligned}
y=638.96+ & 1103.44 A-254.95 B+ \\
+ & 25.25 B A-34.54 \times B^{2}
\end{aligned}
$$

This model was validated with ANOVA before building the response surface graphs presented in Figure 1.

The ANOVA results show that the $\mathrm{pH}(\mathrm{A})$ and ethanol concentration $(B)$ had a significant $(p<0.05)$ effect on the process of anthocyanin extraction (Table 3 ). The $\mathrm{pH}$ effect was linear $(p<0.05)$, indicating that the recovery of anthocyanins increased as the $\mathrm{pH}$ decreased (Figure $1 \mathrm{~A}$ and $\mathrm{B}$ ).

This remark is consistent with the results obtained by Rodrigues et al. [2015], who evaluated the effects of $\mathrm{pH}$ in a range of 0.5 to 6.5 on the optimization of the extraction of anthocyanins from jaboticaba (Myrciaria spp.) skins, and found that anthocyanin recovery was favored at a $\mathrm{pH}$ below 3.5 and above 4 . A previous study [Brouillard, 1982] demonstrated that $\mathrm{pH}$ affected the stability of anthocyanins, since their structure can undergo a reversible transformation in aqueous media, in a $\mathrm{pH}$-dependent manner. The flavylium cation structure predominated at $\mathrm{pH}$ of 1 , while the quinoidal base predominated at $\mathrm{pH}$ between 2 and 4, but the most stable chemical structure of anthocyanins was the flavylium cation.

The concentration of ethanol, both in its linear and quadratic form, had a positive effect on the extraction process (Table 3 and Figure 1C). However, a decrease in the recovery of anthocyanins occurred at ethanol concentrations higher than $70 \%$. The highest recovery of anthocyanins was achieved at ethanol concentration between $60 \%$ and $70 \%$. This is in agreement with previous studies [Khazaei et al., 2016], which showed that the recovery of anthocyanins was facilitated at ethanol levels of $60-70 \%$. Sonication time

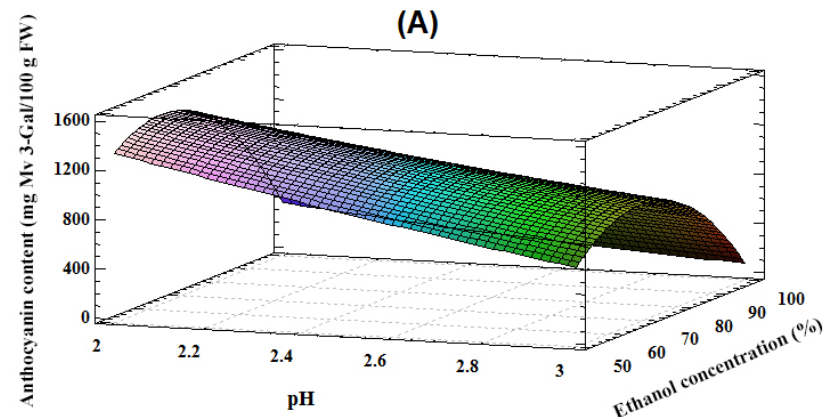

(B)

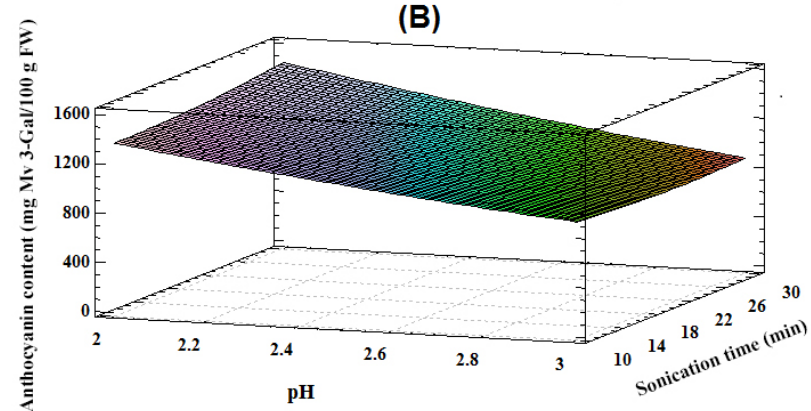

(C)

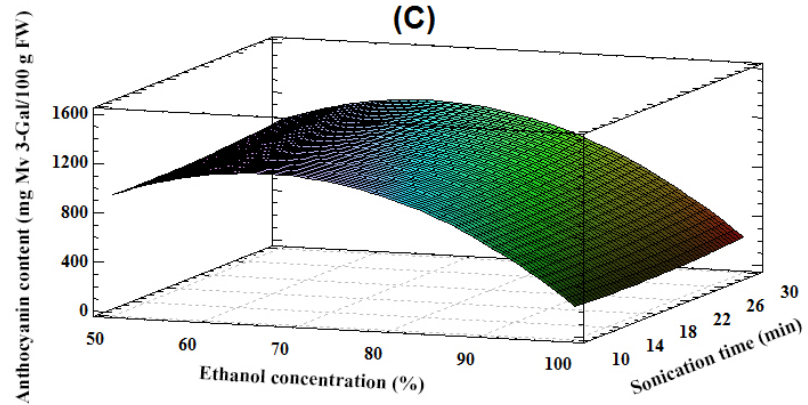

FIGURE 1. Response surface plots of the Box-Behnken design using polynomial equations of the effects of $\mathrm{pH}$ and ethanol concentration (A), $\mathrm{pH}$ and sonication time (B), and ethanol concentration and sonication time $(\mathrm{C})$ on total anthocyanin content of chagalapoli fruit fresh weight (FW). 
showed no significant effect on the recovery of anthocyanins (Figure 1B). The time (min) of sonication tested in the model may not have been sufficient to affect anthocyanin yield. However, sonication as a tool to improve recovery of phytochemicals from vegetal tissue has been highly valued [Rosello-Soto et al., 2015]. The optimized conditions for the extraction of anthocyanins were: ethanol concentration of $63.5 \%$ $(v / v), \mathrm{pH}$ of 2.0, and sonication time of $30 \mathrm{~min}$.

The optimal point was verified experimentally, resulting in an anthocyanin recovery of $1545 \mathrm{mg} \mathrm{Mv}$ 3-Gal equivalents/100 g FW. This value is higher than that reported by Joaquín-Cruz et al. [2015] for the same fruit (796 mg cyanidin-3-O-glucoside equivalents/100 g FW) who used acidified methanol as a solvent and no sonication treatment. The differences among the values reported by Joaquín-Cruz et al. [2015] and in the present study could be due to the type of anthocyanin used to express TAC. The protocol developed in this work could be applied to commercial anthocyanin extraction for food applications due to its single extraction step performed with substances that are safe for use in foods (GRAS classification).

\section{HPLC analysis of chagalapoli fruit anthocyanins}

The chromatogram presented in Figure 2 shows the profile of the anthocyanins extracted from $\mathrm{CF}$ at the optimized extraction conditions, which ensured the highest TAC. Twelve anthocyanins were detected of which the most abundant was malvidin 3-O-galactoside ( $\mathrm{Mv} 3-\mathrm{Gal}$ ), followed by petunidin 3-O-galactoside (Pt 3-Gal) and delphinidin 3-O-galactoside (Dp 3-Gal). These three anthocyanins accounted for approx. $78.4 \%$ of the relative percentage of peak area of the separated anthocyanins. Other anthocyanins detected in $\mathrm{CF}$ were malvidin di $O$-hexoside (peak 2), cyanidin 3-O-galactoside (peak 3 ), delphinidin 3- $O$-arabinoside (peak 5), cyanidin 3- $O$-arabinoside (peak 7), peonidin 3-O-galactoside (peak 8), petunidin 3-O-arabinoside (peak 9), and malvidin 3-O-arabinoside (peak 12). The anthocyanin profile obtained is similar to that reported by Joaquín-Cruz et al. [2015] for CF anthocyanins extracted with acidified methanol and no sonication treatment, which probably means that the anthocyanin profile of $\mathrm{CF}$ is not altered by the extraction conditions, and the procedure defined could be used to enhance anthocyanin recovery from $\mathrm{CF}$.

\section{Microencapsulation process parameters and microcapsule characterization}

Table 4 lists the results of determinations of the variables related to the microencapsulation process, i.e. EE and physicochemical characteristics of the MC. The EE is a variable that relates/describes the ability of wall materials to trap or hold the core material to be encapsulated. High values of EE are associated with low levels of core material on the surface

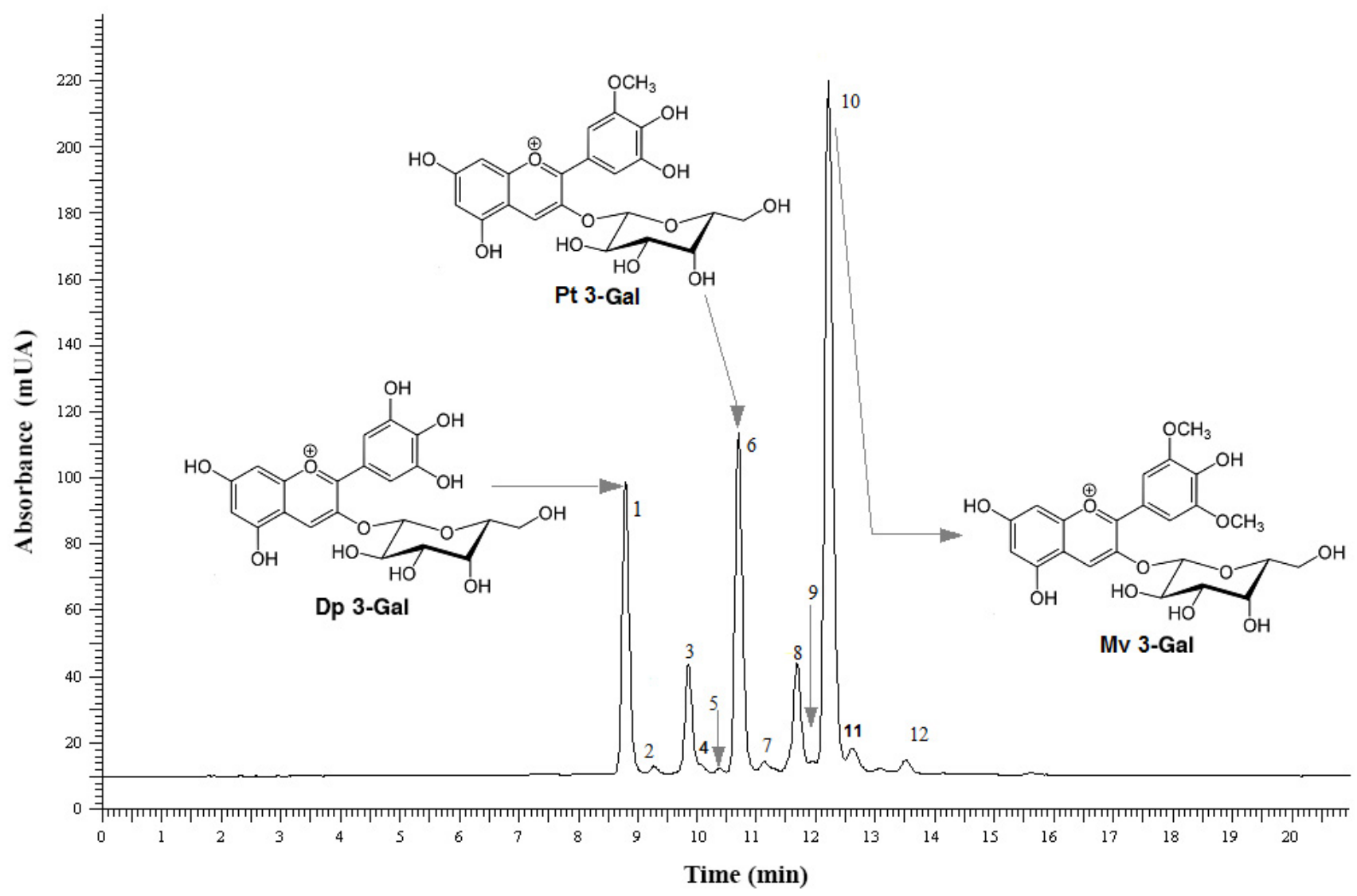

FIGURE 2. RP-HPLC chromatogram of the anthocyanins from chagalapoli fruit (Ardisia compresa Kush).

Anthocyanins were obtained under the optimized extraction process. Pt 3-Gal: petunidin 3-O-galactoside, Mv 3-Gal: malvidin 3- $O$-galactoside, Dp 3-Gal: delphinidin 3-O-galactoside, Gal: galactoside. Peaks 1-12 correspond to different anthocyanins present in the extract. 
TABLE 4. Encapsulation productivity and efficiency and physicochemical characteristics of chagalapoli fruit anthocyanin microcapsules obtained with different combinations of maltodextrin $(\mathrm{M})$ and $\mathrm{Capsul}^{\circledR}(\mathrm{C})$ as wall materials.

\begin{tabular}{l|ccccccc}
\hline Treatments & EP $(\%)$ & EE $(\%)$ & MT $(\mathrm{g} / 100 \mathrm{~g})$ & $\mathrm{a}_{\mathrm{w}}$ & $\mathrm{H}(\mathrm{g} / 100 \mathrm{~g})$ & $\mathrm{S}(\%)$ \\
\hline $100 \mathrm{M}$ & $95.60 \pm 0.76^{\mathrm{b} 1}$ & $99.40 \pm 0.00^{\mathrm{b}}$ & $1.83 \pm 0.12^{\mathrm{c}}$ & $0.15 \pm 0.01^{\mathrm{a}}$ & $13.81 \pm 0.07^{\mathrm{a}}$ & $97.06 \pm 0.08^{\mathrm{b}}$ \\
$75 \mathrm{M} 25 \mathrm{C}$ & $95.71 \pm 0.92^{\mathrm{b}}$ & $99.65 \pm 0.02^{\mathrm{a}}$ & $2.63 \pm 0.07^{\mathrm{a}}$ & $0.13 \pm 0.01^{\mathrm{ab}}$ & $13.15 \pm 0.11^{\mathrm{b}}$ & $97.42 \pm 0.04^{\mathrm{a}}$ \\
$50 \mathrm{M} 50 \mathrm{C}$ & $98.27 \pm 0.55^{\mathrm{a}}$ & $99.66 \pm 0.01^{\mathrm{a}}$ & $2.47 \pm 0.19^{\mathrm{ab}}$ & $0.13 \pm 0.01^{\mathrm{ab}}$ & $11.48 \pm 0.32^{\mathrm{c}}$ & $96.52 \pm 0.11^{\mathrm{c}}$ \\
$25 \mathrm{M} 75 \mathrm{C}$ & $99.25 \pm 0.85^{\mathrm{a}}$ & $99.65 \pm 0.01^{\mathrm{a}}$ & $2.74 \pm 0.40^{\mathrm{a}}$ & $0.11 \pm 0.00^{\mathrm{b}}$ & $11.42 \pm 0.11^{\mathrm{c}}$ & $97.10 \pm 0.11^{\mathrm{b}}$ \\
$100 \mathrm{C}$ & $99.47 \pm 0.19^{\mathrm{a}}$ & $99.67 \pm 0.01^{\mathrm{a}}$ & $1.89 \pm 0.01^{\mathrm{bc}}$ & $0.13 \pm 0.00^{\mathrm{ab}}$ & $10.82 \pm 0.07^{\mathrm{d}}$ & $96.40 \pm 0.20^{\mathrm{c}}$ \\
SMD (0.05) & 1.934 & 0.0311 & 0.6285 & 0.0193 & 0.4889 & 0.3043 \\
\hline
\end{tabular}

EP - encapsulation productivity; EE - encapsulation efficiency; MT - moisture content; $\mathrm{a}_{\mathrm{w}}$ - water activity; H - hygroscopicity; S - solubility; SMD - significant minimum difference. M100: maltodextrin 100\%; 75M25C: $75 \%$ maltodextrin 25\% Capsul ${ }^{\mathrm{w}}$; $50 \mathrm{M} 50 \mathrm{C}$ : 50\% maltodextrin 50\% Capsul ${ }^{\circledR} ; 25 \mathrm{M} 75 \mathrm{C}: 25 \%$ maltodextrin 75\% Capsul ${ }^{\circledR}$; 100C: 100\% Capsul ${ }^{\circledR} .{ }^{1}$ Mean of three repetitions \pm standard deviation. Means with different letters within a given column indicate statistically significant difference $(\mathrm{p}<0.05)$.

of the microcapsule and improved stability of the microencapsulated compound [Mahdavi et al., 2016]. The values obtained for this variable were greater than $99 \mathrm{~g} / 100 \mathrm{~g}$ for all treatments (Table 4).

Although significant differences $(p<0.05)$ were found among the treatments, differences may not be relevant from a practical point of view. Results of this study are similar to those of Norkaew et al. [2019] who reported $100 \mathrm{~g} / 100 \mathrm{~g}$ of EE in the encapsulation of anthocyanins from black rice using maltodextrin and gelatin as wall material, on their own or in combination, but higher compared to the results reported by Righi da Rosa et al. [2019] who microencapsulated blueberry anthocyanins with maltodextrin DE20 and starch "hi-maize" as wall materials. The mentioned authors used similar drying conditions as in this study.

The variables MT, $\mathrm{a}_{\mathrm{w}}$, and $\mathrm{H}$ are important for microcapsule storage, because they are related to the water "status" of the MC, and indeed, with the stability of polysaccharides forming the encapsulating wall. The MT of the microcapsules from the five treatments ranged from 1.83 to $2.74 \mathrm{~g} / 100 \mathrm{~g}$. The lower values were obtained in the treatments with single wall material (Table 4). MT is affected by the feed flow rate and the inlet and outlet temperatures during the spray drying process. It is desirable to have low MT values to enhance storability of the MC. The values obtained are lower than those reported by Silva et al. [2013] for MC of jaboticaba anthocyanins made with $\mathrm{M}(4.84 \mathrm{~g} / 100 \mathrm{~g})$, and a mixture of $\mathrm{M}: \mathrm{C}$ in a 17.7:83.3 ratio $(5.3 \mathrm{~g} / 100 \mathrm{~g})$, obtained under the same drying conditions. The $\mathrm{a}_{\mathrm{w}}$ of microcapsules was between 0.11 and 0.15 . The $\mathrm{a}_{\mathrm{w}}$ values obtained are below the maximum limit of 0.3 required to guarantee the stability of the powders during storage [Tonon et al., 2009]. García-Tejeda et al. [2015] reported $\mathrm{a}_{\mathrm{w}}$ values of 0.19 and 0.26 for anthocyanin MC produced with modified starches derived from normal

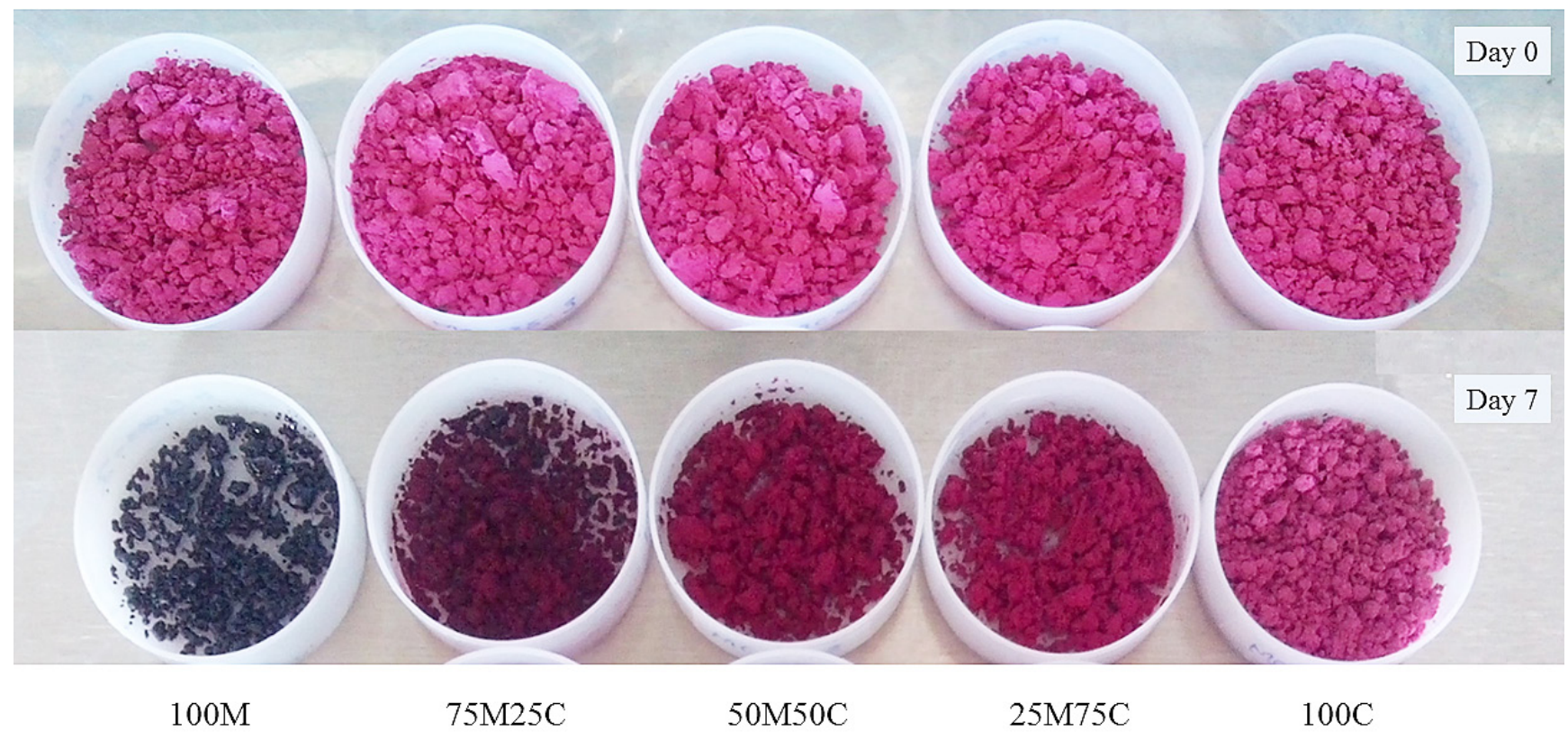

FIGURE 3. Microcapsules of anthocyanins from chagalapoli fruit prepared with different proportions of maltodextrin (M) and Capsul ${ }^{\circledR}(\mathrm{C})$ as wall materials, at the initial day and after one week of storage in open plastic containers at room temperature. 
and waxy maize, respectively. In the case of $\mathrm{MC}$, the variables MT and $\mathrm{a}_{\mathrm{w}}$ are dependent on the drying temperature (inlet and outlet temperatures), with high temperatures resulting in low values of these variables [Frascareli et al., 2012].

The proportion of M:C significantly affected the hygroscopicity of the MC. Greater $\mathrm{H}$ values were observed for treatments with a high proportion of $\mathrm{M}(100 \mathrm{M}$ and $75 \mathrm{M} 25 \mathrm{C})$ in which the particles had an intense pink-red color due to hydration after seven days of storage in open plastic containers (Figure 3). Silva et al. [2013] reported similar results on hygroscopicity of microcapsules prepared using $\mathrm{M}$ and $\mathrm{C}$ mixtures during the encapsulation of jaboticaba anthocyanins.

It is recommended that the $\mathrm{H}$ value of $\mathrm{MC}$ be between 10 and $12 \mathrm{~g} / 100 \mathrm{~g}$ to prevent absorbing moisture from the atmosphere during storage. Microcapsules with high $\mathrm{H}$ ( $>14 \mathrm{~g} / 100 \mathrm{~g}$ ), become soft and thereby lose their protective properties against external agents, such as oxygen, light, and free radicals, which could degrade anthocyanins [Silva et al., 2013].

The solubility (S) of the microcapsules varied from 96.4 to $97.4 \%$, and no effect of $\mathrm{M}$ or $\mathrm{C}$ proportion in the wall material mixtures was observed. The solubility values of the microcapsules obtained were sufficient for the complete incorporation in hydrophilic food systems.

\section{Microcapsule morphology}

The MC were spherical in shape and had different sizes (Figure 4), which is typical of spray-drying generated powders. Mixtures of different wall materials result in different MC morphology. The $100 \mathrm{M}$ treatment produced smaller microspheres with a smoother surface than the treatments in the presence of $\mathrm{C}$, in which spherical $\mathrm{MC}$ predominated,
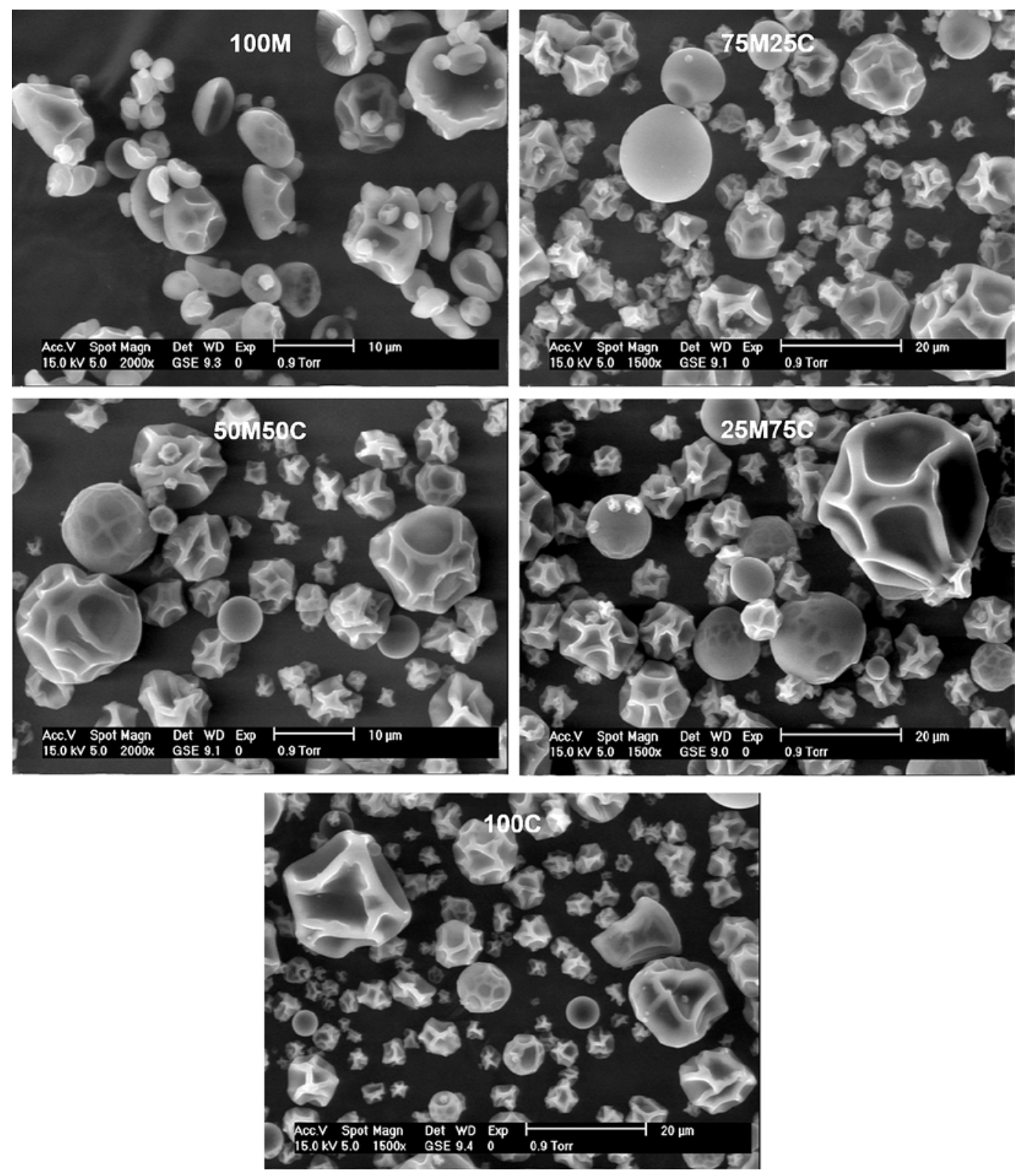

FIGURE 4. External structure of anthocyanin microcapsules of chagalapoli fruit produced using different combinations of wall materials. M100: maltodextrin 100\%; 75M25C: 75\% maltodextrin 25\% Capsul@; 50M50C: 50\% maltodextrin 50\% Capsul@; 25M75C: 25\% maltodextrin 75\% Capsul@; 100C: $100 \%$ Capsul®. 


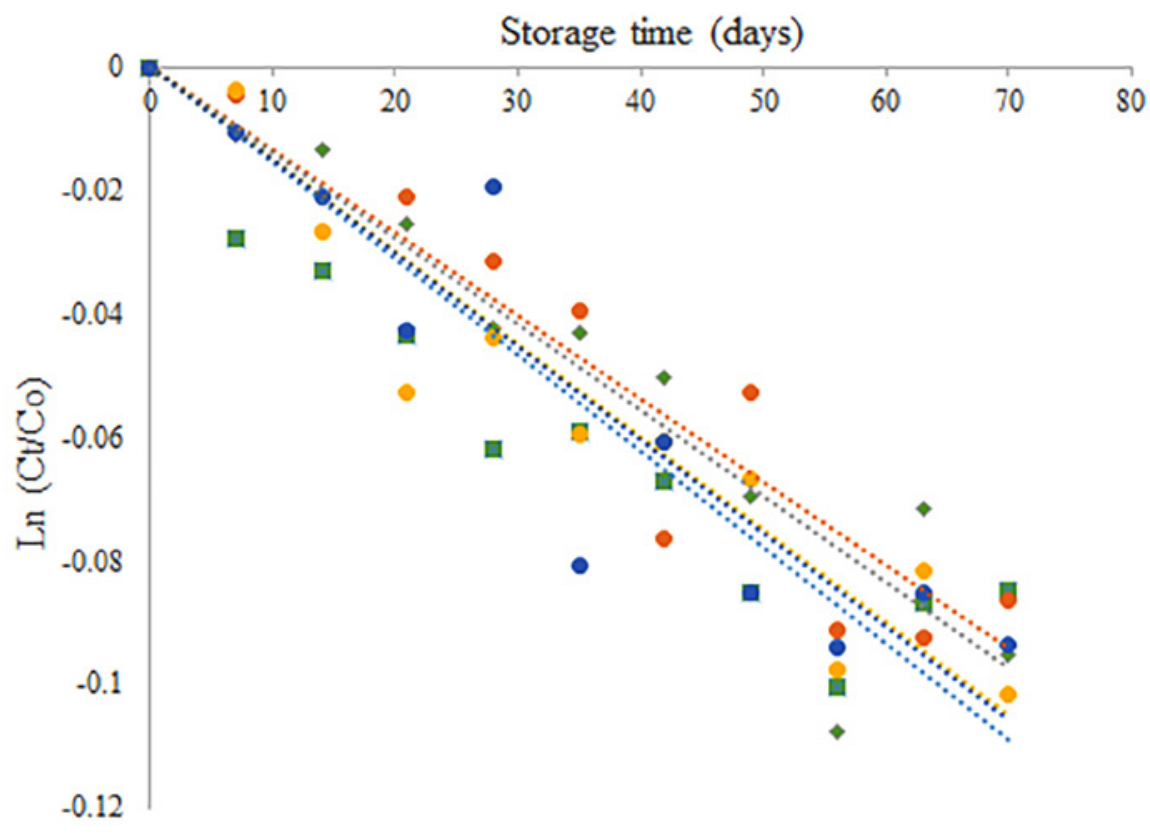

回 $100 \mathrm{M} \bullet 75 \mathrm{M} 25 \mathrm{C} \bullet 50 \mathrm{M} 50 \mathrm{C} \bullet 25 \mathrm{M} 75 \mathrm{C} \bullet 100 \mathrm{C}$

FIGURE 5. Degradation of anthocyanins in microcapsules stored at $35^{\circ} \mathrm{C}$ as a logarithm of the content ratio at storage time $\mathrm{t}\left(\mathrm{C}_{\mathrm{t}}\right)$ and initial $\left(\mathrm{C}_{0}\right)$.

Microcapsules produced using different combinations of wall materials; M100: maltodextrin 100\%; 75M25C: 75\% maltodextrin-25\% Capsul ${ }^{\circledR}$; 50M50C: 50\% maltodextrin 50\% Capsul ${ }^{\circledR} ; 25$ M75C: 25\% maltodextrin 75\% Capsul ${ }^{\circledR}$; 100C: 100\% Capsul ${ }^{\circledR}$.

but with a rough surface, that according to Tonon et al. [2009] is attributed to the shrinkage of the particles due to the loss of moisture and cooling. The morphological characteristics observed in the MC from the different treatments are similar to those described by Silva et al. [2013] for MC of jaboticaba anthocyanins with $\mathrm{M}$ and $\mathrm{C}$ as wall materials. The smooth spheroidal morphology of $\mathrm{MC}$ with $\mathrm{M}$ as the wall material is related to the content of low molecular weight sugars in this polysaccharide, which can act as a plasticizer and prevent shrinkage during surface drying. Loksuwan [2007] reached this conclusion after comparing the morphology characteristics of microcapsules prepared with wall materials with different dextrose equivalents (DE). As stated by Barros \& Stringheta [2006], MC with intact and regular walls result in an improved microencapsulation process because those with rough surfaces have larger contact areas than those with smooth surfaces, which can render them more susceptible to degradation. The MC had average diameters of $5.1 \mu \mathrm{m}$ (100M), $5.3 \mu \mathrm{m}$ (75M25C), $6.7 \mu \mathrm{m}$ (50M50C), $5.8 \mu \mathrm{m}$ (25M75C), and $6.1 \mu \mathrm{m}(100 \mathrm{C})$. These values are lower than the average diameter of $10.9 \mu \mathrm{m}$ reported for $10 \mathrm{DE}$ maltodextrin microcapsules by Tonon et al. [2009].

\section{Stability of anthocyanin microcapsules during storage}

The degradation of anthocyanins in the MC fitted the first order kinetic model (Figure 5), as reported previously by Idham et al. [2012]. The $\mathrm{R}^{2}$ for the anthocyanin stability data of the different wall materials were $>0.8$ (Table 5). The $\mathrm{R}^{2}$ value is an indicator of how the data fit to the model used to explain the phenomenon. The wall material treatments that fitted better were 50M50C and 25M75C.
Righi da Rosa et al. [2019] evaluated the stability of blackberry microencapsulated anthocyanins with $\mathrm{M}$ and modified maize starch (hi-maize) over 20 days, reporting $\mathrm{R}^{2}$ values of 0.9678 to 0.9809 for the data adjusted to the first order model.

The degradation constant of the microencapsulated $\mathrm{CF}$ anthocyanins ranged from $1.35 \times 10^{-3}$ to $1.65 \times 10^{-3}$ day $^{-1}$, which resulted in a half-life time which ranged from 424 to 520 days (Table 5). The stability of the microencapsulated anthocyanins during storage is attributed to the favorable characteristics of the MC related to stability, such as moisture content (MT), water activity $\left(\mathrm{a}_{\mathrm{w}}\right)$, and hygroscopicity $(\mathrm{H})$. Moser et al. [2017] reported a half-life time of 545 days for grape anthocyanin microencapsulated with blends of soy

TABLE 5. Degradation kinetic variables of the anthocyanin microcapsules during storage at $35^{\circ} \mathrm{C}$.

\begin{tabular}{lccccc}
\hline $\begin{array}{l}\text { Wall } \\
\text { material }\end{array}$ & $\mathrm{R}^{2}$ & $\begin{array}{c}\mathrm{k} \times 10^{-3} \\
(1 / \text { days })\end{array}$ & $\begin{array}{c}\text { Half-life } \mathrm{t}_{1 / 2} \\
(\text { days })\end{array}$ & $\begin{array}{c}\mathrm{AR} \\
(\%)\end{array}$ \\
\hline $100 \mathrm{M}$ & 0.8143 & 1.35 & $520 \pm 82$ & $90.3 \pm 1.4$ \\
$75 \mathrm{M} 25 \mathrm{C}$ & 0.8254 & 1.65 & $424 \pm 54$ & $89.5 \pm 2.0$ \\
$50 \mathrm{M} 50 \mathrm{C}$ & 0.9100 & 1.50 & $464 \pm 44$ & $91.0 \pm 0.8$ \\
$25 \mathrm{M} 75 \mathrm{C}$ & 0.9258 & 1.60 & $451 \pm 62$ & $89.0 \pm 1.2$ \\
$100 \mathrm{C}$ & 0.8520 & 1.60 & $451 \pm 62$ & $91.0 \pm 1.2$ \\
\hline
\end{tabular}

$\mathrm{M}$ - maltodextrin; C - Capsul ${ }^{\oplus ;}$ AR - anthocyanin retention. M100: maltodextrin 100\%; 75M25C: 75\% maltodextrin 25\% Capsul@; 50M50C: 50\% maltodextrin 50\% Capsul@; 25M75C: 25\% maltodextrin 75\% Capsul®; 100C: 100\% Capsul ${ }^{\circledR}$. 
protein and maltodextrin, stored at $35^{\circ} \mathrm{C}$. Stability of the core materials in the $\mathrm{MC}$ is affected by the EE during the microencapsulation process in a direct manner. The higher the EE, the longer the stability of the microencapsulated compounds [Li et al., 2018]. Anthocyanin retention (AR) in the MC prepared with the different wall material mixtures after 70 days of storage at $35^{\circ} \mathrm{C}$ and protected from light, ranged from 89.0 to $91.0 \%$.

The initial color parameters $\left(\mathrm{L}^{*}, \mathrm{a}^{*}\right.$, and $\left.\mathrm{b}^{*}\right)$ of the MC were of 37.9, 39.4, and -4.1 for $100 \mathrm{M} ; 40.3,39.2$ and -4.6 for $75 \mathrm{M} 25 \mathrm{C} ; 44.3,38.8$ and -5.3 for $50 \mathrm{M} 50 \mathrm{C} ; 45.9,39.7$, and -5.5 for $25 \mathrm{M} 75 \mathrm{C}$; and $48.1,39.9$, and -5.8 for $100 \mathrm{C}$ (Figure 6A). The incorporation of $\mathrm{C}$ in the wall material blends resulted in the brightest $\mathrm{MC}$ which had the highest value of $\mathrm{L}^{*}$ in the treatment $100 \mathrm{C}$. The values of $\mathrm{a}^{*}$ were less affected; however, MC from the $25 \mathrm{M} 75 \mathrm{C}$ and $100 \mathrm{C}$ treatments had higher values of this variable, which means that their $\mathrm{MC}$ were of a light red color (Figure 6B), while b* values decreased with increasing $\mathrm{C}$ proportion in the blends, which means that the color of the MC increased to blue tint (Figure 6C). The color of the MC is affected both, by the wall materials used, and the chemical structure of the anthocyanins microencapsulated [Norkaew et al., 2019]. In some cases, color changes are marked, as in the study of Norkaew et al. [2019], who when incorporating whey protein in mixtures with $\mathrm{M}$ or gum Arabic obtained intense dark MC; while in others [Idham et al., 2012], combinations of M with gum Arabic as wall materials caused slight changes in the color parameters.

Storage resulted in color change of the MC. The $\mathrm{L}^{*}$ values increased from 0.05 to $12.1 \%$, meaning that the MCs became clearer and brighter at the end of storage. The smallest changes in $\mathrm{L}^{*}$ were presented in the $\mathrm{MC}$ with a higher proportion of $\mathrm{C}$ in the wall material mixture (Figure 6A). The variations on $\mathrm{a}^{*}$ were lower ( 0.7 to $2.9 \%$ ), with no significant differences of $\mathrm{a}^{*}$ values between the $25 \mathrm{M} 75 \mathrm{C}$ and $100 \mathrm{C} \mathrm{MC}$ treatments (Figure 6B). The $\mathrm{b}^{*}$ values decreased in the $100 \mathrm{M}, 75 \mathrm{M} 25 \mathrm{C}$ and $50 \mathrm{M} 50 \mathrm{C} \mathrm{MC}$ treatments, meaning that with storage the yellowness was reduced, while blueness increased. In the $25 \mathrm{M} 75 \mathrm{C}$ and $100 \mathrm{C}$ MC variants, no differences of $b^{*}$ values were observed between 0 and 70 days of storage (Figure $6 \mathrm{C}$ ). According to these results, incorporation of $\mathrm{C}$ in the wall material blends to prepare the MC improved the color stability.

\section{CONCLUSIONS}

Among the variables examined to optimize the extraction of anthocyanins from CF, only the ethanol concentration and $\mathrm{pH}$ contributed significantly to the model that showed the best fit to the experimental data $\left(\mathrm{R}^{2}=0.9760\right)$. The optimized extracting conditions were $63.5 \%(v / v)$ ethanol as a solvent, $\mathrm{pH}$ of 2 , sonication time of $30 \mathrm{~min}$, and a ratio of fruit pulp to solvent of 1:5 (w/v). Anthocyanins from CF can be encapsulated with a mixture of maltodextrin:Capsul ${ }^{\circledR}$ in a 50:50 ratio, with a high product encapsulation efficiency and microcapsules characteristics favorable for storage. Under the conditions used to prepare the microcapsules of $\mathrm{CF}$ anthocyanins in this study, and the storage conditions applied; the half-life time of the microcapsules was longer than one year. The incorporation of Capsul ${ }^{\circledR}$ in the blends of wall
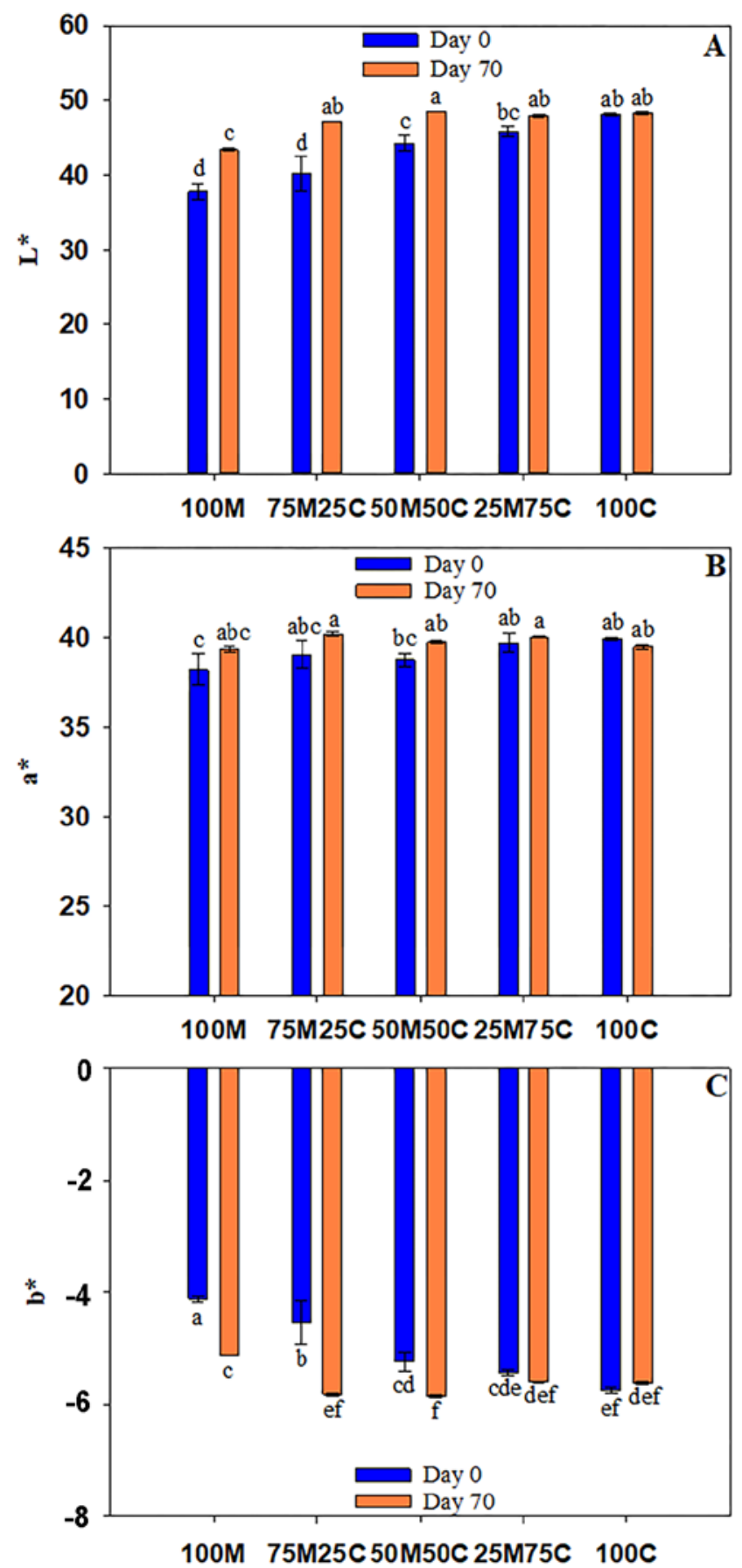

FIGURE 6. Color parameters of the microcapsules of chagalapoli fruit anthocyanins at 0 and 70 days of storage at $35^{\circ} \mathrm{C}$; lightness $-\mathrm{L}^{*}(\mathrm{~A})$, redness - $\mathrm{a}^{*}(\mathrm{~B})$, and yellowness $-\mathrm{b}^{*}(\mathrm{C})$.

Microcapsules produced using different combinations of wall materials; M100: maltodextrin 100\%; 75M25C: 75\% maltodextrin 25\% Capsul®; 50M50C: 50\% maltodextrin 50\% Capsul ; 25M75C: 25\% maltodextrin 75\% Capsul@; 100C: 100\% Capsul $®$. Different letters above the bars indicate significant differences $(\mathrm{p}<0.05)$.

materials improved color stability of the microcapsules during storage. Chagalapoli fruit is a suitable source of anthocyanins and due to its particular anthocyanin profile, dominated by malvidin derivatives, its anthocyanin microcapsules could be used in foods to get shades of color that are not possible to achieve with the common anthocyanin pigments based on cyanidin derivatives. 


\section{ACKNOWLEDGEMENTS}

V.A.G acknowledges CONACYT, Mexico for a scholarship for her Master Science studies (Registration number: 554465).

\section{CONFLICT OF INTERESTS}

Authors declare they do not have any conflict of interests.

\section{ORCID IDs}

I. Andrade-González http://orcid.org/0000-0002-4004-6308 F. Hernández-Rosas https://orcid.org/0000-0003-3718-3245 J.A.Herrera-Corredorhttps://orcid.org/0000-0002-2392-2521 F. Martínez-Bustos https://orcid.org/0000-0002-2132-5598 Y. Salinas-Moreno https://orcid.org/0000-0001-8145-2225

\section{REFERENCES}

1. AACC (1995). Approved Methods of the American Association of Cereal Chemists, 9 th ed. International, St. Paul, MN, Method. 44-19.

2. Arrazola, G., Herazo, I., Alvis, A. (2014). Anthocyanin microencapsulation of eggplant (Solanum melongena L.) and evaluation of color stability and antioxidant capacity. Información Tecnológica, 25(3), 31-42 (in Spanish; English abstract). https://doi.org/10.4067/S0718-07642014000300006

3. Barros, F.A.R.D., Stringheta, P.C. (2006). Anthocyanin microencapsulation - an alternative to increase its applicability as a food ingredient. Biotecnologia Ciência e Desenvolvimento, 36, 18-24 (in Portuguese; English abstract).

4. Bendokas, V., Skemiene, K., Trumbeckaite, S., Stanys, V., Passamonti, S., Borutaite, V., Liobikas, J. (2020). Anthocyanins: From plant pigments to health benefits at mitochondrial level. Critical Reviews in Food Science and Nutrition, 60(19), 3352-3365.

https://doi.org/10.1080/10408398.2019.1687421

5. Brouillard, R. (1982). Chemical structure of anthocyanins. In P. Markakis (Ed.), Anthocyanins as Food Colors, New York: Academic Press, pp. 1-40.

https://doi.org/10.1016/B978-0-12-472550-8.50005-6

6. de Brito, E.S., de Araujo, M.C.P., Alves, R.E., Carkeet, C., Clevidence, B.A. Novotny, J.A. (2007). Anthocyanins present in selected tropical fruits: Acerola, jambolão, jussara, and guajiru. Journal of Agricultural and Food Chemistry, 55(23), 9389-9394. https://doi.org/10.1021/jf0715020

7. Escobar-Puentes, A.A., García-Gurrola, A., Rincón, S., Zepeda, A., Martínez-Bustos, F. (2020). Effect of amylose/amylopectin content and succinylation on properties of corn starch nanoparticles as encapsulants of anthocyanins. Carbohydrate Polymers, 250, art. no. 116972 .

https://doi.org/10.1016/j.carbpol.2020.116972

8. Fossen, T., Slimestad, R., Andersen, O.M. (2001). Anthocyanins from maize (Zea mays) and reed canary grass (Phalaris arundinacea). Journal of Agricultural and Food Chemistry, 49(5), 2318-2321.

https://doi.org/10.1021/jf001399d

9. Frascareli, E.C., Silva, V.M., Tonon, R.V., Hubinger, M.D. (2012). Effect of process conditions on the microencapsulation of coffee oil by spray drying. Food and Bioproducts Processing, 90(3), 413-424.

https://doi.org/10.1016/j.fbp.2011.12.002

10. García-Tejeda, Y.V., Salinas-Moreno, Y., Martínez-Bustos, F. (2015). Acetylation of normal and waxy maize starches as encapsulating agents for maize anthocyanins microencapsulation. Food and Bioproducts Processing, 94, 717-726.

https://doi.org/10.1016/j.fbp.2014.10.003

11. Ghafoor, K., Hui, T., Choi, Y. H. (2011). Optimization of ultrasonic-assisted extraction of total anthocyanins from grape peel using response surface methodology. Journal of Food Biochemistry, 35(3), 735-746.

https://doi.org/10.1111/j.1745-4514.2010.00413.x

12. Giusti, M.M., Wrolstad, R.E. (2001). Anthocyanins. Characterization and measurement of anthocyanins by UV-visible spectroscopy. In R.E. Wrolstad (Ed.), Current Protocols in Food Analytical Chemistry. John Wiley \& Sons, New York, USA; unit F1.2.1-1.

https://doi.org/10.1002/0471142913.faf0102s00

13. Giusti, M.M., Wrolstad, R.E. (2003). Acylated anthocyanins from edible sources and their applications in food systems. Biochemical Engineering Journal, 14(3), 217-225.

https://doi.org/10.1016/S1369-703×(02)00221-8

14. Idham, Z., Muhamad, I.I., Sarmidi, M.R. (2012). Degradation kinetics and color stability of spray-dried encapsulated anthocyanins from Hibiscus sabdariffa L. Journal of Food Processing Engineering, 35(4), 522-542. https://doi.org/10.1111/j.1745-4530.2010.00605.x

15. Joaquín-Cruz, E., Dueñas, M., García-Cruz, L., Salinas-Moreno, Y., Santos-Buelga, C., García-Salinas, C. (2015). Anthocyanin and phenolic characterization, chemical composition and antioxidant activity of chagalapoli (Ardisia compressa K.) fruit: A tropical source of natural pigments. Food Research International, 70, 151-157.

https://doi.org/10.1016/j.foodres.2015.01.033

16. Khazaei, K.M., Jafari, S., Ghorbani, M., Kakhki, A.H., Sarfarazi, M. (2016). Optimization of anthocyanin extraction from saffron petals with response surface methodology. Food Analytical Methods, 9, 1993-2001.

https://doi.org/10.1007/s12161-015-0375-4

17. Labuza, T.P., Schmidl, M.K. (1985). Accelerated shelf-life testing of foods. Food Technology, 39(9), 57-62.

18. Li, Y.B., Wu, L., Weng, M.J., Tang, B.S., Lai, P.F., Chen, J.C. (2018). Effect of different encapsulating agent combinations on physicochemical properties and stability of microcapsules loaded with phenolics of plum (Prunus salicina Lindl.). Powder Technology, 340, 459-464.

https://doi.org/10.1016/j. powtec.2018.09.049

19. Loksuwan, J. (2007). Characteristics of microencapsulated $\beta$-carotene formed by spray drying with modified tapioca starch, native tapioca starch and maltodextrin. Food Hydrocolloids, 2l(5-6), 928-935.

https://doi.org/10.1016/j.foodhyd.2006.10.011

20. Luzardo-Ocampo, I., Ramírez-Jiménez, A.K., Yañez, J., Mojica, L., Luna-Vital, D.A. (2021). Technological applications of natural colorants in food systems: A review. Foods, 10(3), art. no. 634 . https://doi.org/10.3390/foods10030634

21. Mahdavi, S.A., Jafari, S.M., Assadpour, E., Ghorbani, M. (2016). Storage stability of encapsulated barberry's anthocyanin 
and its application in jelly formulation. Journal of Food Engineering, 181, 59-66.

https://doi.org/10.1016/j.jfoodeng.2016.03.003

22. Moreno, S.Y., Sánchez, G.S., Hernández, D.R., Lobato, N.R (2005). Characterization of anthocyanin extracts from maize kernels. Journal of Chromatography Science, 43(9), 483-487. https://doi.org/10.1093/chromsci/43.9.483

23. Moser, P., Nicoletti-Telis, V.R., de Andrade Neves, N., García-Romero, E., Gomez-Alonso, S., Hermosín-Gutiérrez, I. (2017). Storage stability of phenolic compounds in powdered BRS Violeta grape juice microencapsulated with protein and maltodextrin blends. Food Chemistry, 214, 308-318. https://doi.org/10.1016/j.foodchem.2016.07.081

24. Najafabadi, N.S., Sahari, M.A., Barzegar, M., Esfahani, Z.H. (2020). Role of extraction conditions in the recovery of some phytochemical compounds of the jujube fruit. Journal of Agricultural Science and Technology, 22 (2), 439-451.

25. Norkaew, O., Thitisut, P., Mahatheeranont, S., Pawin, B., Sookwong, P., Yodpitak, S., Lungkaphin, A. (2019). Effect of wall materials on some physicochemical properties and release characteristics of encapsulated black rice anthocyanin microcapsules. Food Chemistry, 294, 493-502.

https://doi.org/10.1016/j.foodchem.2019.05.086

26. Pedro, A.C., Granato, D., Rosso, N.D. (2016). Extraction of anthocyanins and polyphenols from black rice (Oryza sativa L.) by modeling and assessing their reversibility and stability. Food Chemistry, 191, 12-20.

https://doi.org/10.1016/j.foodchem.2015.02.045

27. Righi da Rosa, J., Nunes, G.L., Motta, M.H., Fortes, J.P., Cezimbra-Weis, G.C., Rychecki-Hecktheuer, L.H., Muller, E.I., de Menezes, C.R., Severo da Rosa, C. (2019). Microencapsulation of anthocyanin compounds extracted from blueberry (Vaccinium spp.) by spray drying: Characterization, stability and simulated gastrointestinal conditions. Food Hydrocolloids, 89, 742-748. https://doi.org/10.1016/j.foodhyd.2018.11.042

28. Robert, P., Gorena, T., Romero, N., Sepulveda, E., Chavez, J., Saenz, C. (2010). Encapsulation of polyphenols and anthocyanins from pomegranate (Punica granatum) by spray drying. International Journal of Food Science and Technology, 45(7), 1386-1394. https://doi.org/10.1111/j.1365-2621.2010.02270.x

29. Rocha, G.A., Fávaro-Trindade, C.S., Ferreira Grosso, C.R. (2012). Microencapsulation of lycopene by spray drying: Characterization, stability and application of microcapsules. Food Bioproducts Processing, 90(1), 37-42. https://doi.org/10.1016/j.fbp.2011.01.001
30. Rodrigues, S., Fernandes, F.A.N., de Brito, E.S., Sousa, A.D., Narain, N. (2015). Ultrasound extraction of phenolics and anthocyanins from jabuticaba peel. Industrial Crops and Products, 69, 400-407.

https://doi.org/10.1016/j.indcrop.2015.02.059

31. Roselló-Soto, E., Galanakis, C.M., Brnčic, M., Orlien, V., Trujillo, F.J., Mawson, R., Barba, F.J. (2015). Clean recovery of antioxidant compounds from plant foods, by-products and algae assisted by ultrasounds processing. Modeling approaches to optimize processing conditions. Trends in Food Science \& Technology, 42(2), 134-149.

https://doi.org/10.1016/j.tifs.2015.01.002

32. Silva, P.I., Stringheta, P.C., Teófilo, R.F., Nolasco de Oliveira, I.R. (2013). Parameter optimization for spray-drying microencapsulation of jaboticaba (Myrciaria jaboticaba) peel extracts using simultaneous analysis of responses. Journal of Food Engineering, 117(4), 538-544.

https://doi.org/10.1016/j.jfoodeng.2012.08.039

33. Swamy, G.J., Sangamithra, A., Chandrasekar, V. (2014). Response surface modeling and process optimization of aqueous extraction of natural pigments from Beta vulgaris using Box-Behnken design of experiments. Dyes and Pigments, 111, 64-74. https://doi.org/10.1016/j.dyepig.2014.05.028

34. Tarone, A.G., Cazarin, C.B.B., Marostica Junior, M.R. (2020). Anthocyanins: New techniques and challenges in microencapsulation. Food Research International, 133, art. no. 109092. https://doi.org/10.1016/j.foodres.2020.109092

35. Tonon, R.V., Brabet, C., Hubinger, M.D. (2010). Anthocyanin stability and antioxidant activity of spray-dried açai (Euterpe oleracea Mart.) juice produced with different carrier agents. Food Research International, 43(3), 907-914. https://doi.org/10.1016/j.foodres.2009.12.013

36. Tonon, R.V., Brabet, C., Pallet, D., Brat, P., Hubinger, M.D. (2009). Physicochemical and morphological characterization of açai (Euterpe oleracea Mart.) powder produced with different carrier agents. International Journal of Food Science \& Technology, 44(10), 1950-1958. https://doi.org/10.1111/j.1365-2621.2009.02012.x

37. Turchiuli, C., Fuchs, M., Bohin, M., Cuvelier, M.E., Ordonnaud, C., Peyrat-Maillard, M.N., Dumoulin, E. (2005). Oil encapsulation by spray drying and fluidised bed agglomeration. Innovative Food Science and Emerging Technologies, 6(1), 29-35. https://doi.org/10.1016/j.ifset.2004.11.005 